\title{
Inhibitory effect of novel iron chelator, 1-(N-acetyl- 6-aminohexyl)-3-hydroxy-2-methylpyridin-4-one (CM1) and green tea extract on growth of Plasmodium falciparum
}

\author{
Somdet Srichairatanakool ${ }^{1 *}$, Supalerk Thipubol ${ }^{1}$, Wachiraporn Tipsuwan ${ }^{2}$, Chairat Uthaipibull ${ }^{3}$ \\ From Challanges in malaria research: Core science and innovation \\ Oxford, UK. 22-24 September 2014
}

\section{Background}

Iron is an essential micronutrient required by all living organisms including malaria parasites (Plasmodium spp.) for many biochemical reactions, especially growth and multiplication processes. Therefore, the malaria parasites needs to take up the iron from outside or/and inside the parasitized red blood cells (PRBC). Iron chelators are widely used for treatment of thalassemia-related iron overload and also inhibit parasite growth at levels which are non-toxic to mammalian cells.

\section{Materials and methods}

The inhibitory effect of 1-(N-acetyl-6-amino-hexyl)-3hydroxypyridin-4-one (CM1) and green tea extract (GTE) on the growth of malaria parasite $P$. falciparum was investigated compared with standard chelators including desferrioxamine (DFO), deferiprone (DFP) and deferasirox (DFX). A flow cytometric technique was used to enumerate the PRBC stained with SYBR Green I fluorescent dye. Labile iron pool (LIP) was assayed using calcein-acetomethoxy (Calcein-AM) fluorescent method.

\section{Results}

The $\mathrm{IC}_{50}$ values of DFO, GTE, CM1, DFX and DFP against $P$. falciparum were $14.09,21.11,35.14,44.71$ and $58.25 \mu \mathrm{M}$, respectively. Importantly, CM1 was more effective in reducing LIP level in the P. falciparum culture than DFP $(P<0.05)$.

\section{Conclusions}

CM1 and GTE exhibit anti-malarial activity. They could interfere with uptake of exogenous iron or deplete intracellular labile iron in malaria parasites, leading to inhibition of their growth.

\section{Acknowledgements}

The work has been supported by the Thailand Graduate Institute of Science and Technology (TGIST), National Science and Technology Development Agency (NSTDA) and Faculty of Medicine, Chiang Mai University.

\section{Authors' details}

${ }^{1}$ Chiang Mai University, Chiang Mai, Thailand. ${ }^{2}$ University of Phayao, Phayao, Thailand. ${ }^{3}$ National Science and Technology Development Agency, Pathum Thani, Thailand.

Published: 22 September 2014

doi:10.1186/1475-2875-13-S1-P84

Cite this article as: Srichairatanakool et al:: Inhibitory effect of novel iron chelator, 1-(N-acetyl-6-aminohexyl)-3-hydroxy-2-methylpyridin-4-one (CM1) and green tea extract on growth of Plasmodium falciparum. Malaria Journal 2014 13(Suppl 1):P84.

Submit your next manuscript to BioMed Central and take full advantage of:

- Convenient online submission

- Thorough peer review

- No space constraints or color figure charges

- Immediate publication on acceptance

- Inclusion in PubMed, CAS, Scopus and Google Scholar

- Research which is freely available for redistribution 